\title{
Characterization of the phosphate adsorption and morphology of sediment particles under simulative disturbing conditions
}

\author{
Tao Li ${ }^{\mathrm{a}, *}$, Dongsheng Wang ${ }^{\mathrm{a}}$, Bin Zhang ${ }^{\mathrm{a}, \mathrm{b}}$, Huijuan Liu ${ }^{\mathrm{a}}$, Hongxiao Tang ${ }^{\mathrm{a}}$ \\ a State Key Laboratory of Environmental Aquatic Chemistry, Research Center for Eco-Environmental Sciences, \\ Chinese Academy of Sciences, Beijing, PR China \\ ${ }^{\mathrm{b}}$ College of Chemical and Environmental Engineering, China University of Mining \& Technology, Beijing, PR China
}

Received 14 March 2006; received in revised form 26 April 2006; accepted 27 April 2006

Available online 4 May 2006

\begin{abstract}
The behavior of nutrient release and adsorption from sediments was influenced by hydrodynamic disturbance significantly. The resuspension/sedimentation processes of sediment particles and phosphate adsorption in Taihu Lake were investigated under different disturbing intensity by utilizing simulative conditions. The effect of morphological characteristics of suspended particles on phosphate adsorption was also studied. In order to elucidate the characteristics of particles suspended by disturbance, the size and structure of particles during different time were monitored on-line by using photometric dispersion and particles image analysis. The method of fractal geometry to explore the morphology characteristics of particles was also used. The results showed that sediments suspended obviously and the phosphate concentration of overlying water decreased rapidly when strong disturbance was applied. Moreover, two different disturbing conditions, one was static condition without wind and the other was weak disturbing intensity with slow wind velocity, following heavy disturbance were compared, and it turned out that the turbidity and phosphate concentration were lower in the latter because the size and the structure of suspended particles were more favorable in the latter disturbing condition. The flocculation index of suspended particles was 0.25 and characteristic length was $30 \mu \mathrm{m}$ under $100 \mathrm{rpm}$ disturbance; comparatively, when heavy disturbance increased to $120 \mathrm{rpm}$, the flocculation index grew up to 0.60 and the characteristic length was greater than $60 \mu \mathrm{m}$. The fractal dimensions of suspended particles were between 1.65 and 1.92 .
\end{abstract}

(C) 2006 Elsevier B.V. All rights reserved.

Keywords: Sediment; Phosphate; Adsorption; Flocculation index; Fractal dimension

\section{Introduction}

Phosphorus has long been considered as a paramount factor for the water quality of lakes. If phosphorus loading is excessive, phytoplankton increases and this has significant negative implications for the overall water quality $[1,2]$. The interactions between dissolved phosphorus and sediments in aquatic systems are important factors controlling concentrations in many natural waters and determining the ultimate fate of inorganic phosphorus in natural systems. In shallow lakes, the cycling of phosphorus between overlying water and bottom sediments was strongly influenced by resuspension of particulate matter. The release and adsorption of phosphorus by sediments resuspension

\footnotetext{
* Correspondance to: P.O. Box 2871, Beijing 100085, China. Tel.: +8610 62849143; fax: +861062923543.

E-mail address: litao221@ hotmail.com (T. Li).
}

are related to physical disturbance such as waves, currents and storms. Reddy et al. [3] measured the P flux during sediment resuspension under laboratory conditions using intact sediment cores and found that resuspension flux of $\mathrm{P}$ was higher than diffusion flux. Kristersen et al. [4] showed that annual internal P loading was over 200 times the annual external P loading as a result of the internal nutrient loading through wind-induced sediment resuspension in shallow Lake Arreso, Denmark. Moreover, resuspension of lake sediments is a function of the bottom shear stress as the result of fluid motion and the local sediment characteristics $[5,6]$.

Strictly speaking, the behaviors of nutrient release and adsorption in shallow lake and deep lake are obviously different, for instance, the sediments of shallow lake are disturbed by wind and the resuspension happen frequently [7,8]. At present, the influence of sediments resuspension on lake ecological system is paid much attention [9-11]. Meanwhile, the effect of strong winds on the suspended solids concentration in shallow lakes 
has been well documented [12,13], especially in shallow lake. Søndergaard et al. [8] concluded that phosphorus release from sediments increased 20-30-fold during resuspension events in a shallow Danish lake. Ogilvie and Mitchell [14] modified the release rates of regenerated dissolved nutrients from the sediments resuspension. Qin et al. [15] analyzed the influence on sediments suspension by wave and current of Taihu Lake, considered that the sediments suspended extensively when wind velocity was above $6.5 \mathrm{~m} / \mathrm{s}$. Fan et al. [16] estimated the phosphorus contribution to overlying water from sediments under wind disturbance in Taihu Lake. Zhu et al. [17] investigated the effect of wave disturbance on the nutrient release from Taihu lake sediments by simulated flume experiments and pointed out that strong disturbance significantly increased the concentration of soluble phosphorus in overlying water.

The interface between sediments and overlying water is not steady. Shear-force by wind influences on the interface frequently, as a result, the sediment particles resuspend and the steady interface is destroyed. Meanwhile, the behaviors of nutrient release and adsorption are affected by the disturbance. Under the disturbing conditions, particles on the surface of sediments swarm into overlying water and the processes, such as resuspension, precipitation, breakage and re-growth of particles, happen instantaneously. During these processes, the structure, porosity and size of particles change, furthermore, the morphological transformation of particles can affect the behaviors of nutrient release and adsorption. However, there is limited investigation available about the influence on the behaviors of nutrient release and adsorption by the particle morphology. Therefore, the main objective of this investigation was to explore the influence on the phosphorus adsorption by the particle morphology under disturbing conditions.

Generally, the aggregates formed by suspended particles are irregular, not spherical, and exhibit the fractal nature. Therefore, fractal characteristics play an important role in the behavior of aggregated particles. Irregular aggregate shapes have been described by fractal geometry concept, and complete characterization of a particle suspension should include a description of the fractal dimension of the aggregates $[18,19]$. As we known, shapes scale defined by Euclidean geometry according to their sizes were integer powers, but fractal objects scale defined by fractal geometry were fractal powers. In fractal geometry, branched objects with irregular boundaries can be defined by non-linear relationships where the properties of the object scale with a characteristic length dimension raised to a power called the fractal dimension. For example, the two-dimensional fractal dimension is defined by a power law relation between projected area $(A)$ and the characteristic length of the aggregates, $l$.

$A \sim l^{D_{2}}$

where $D_{2}$ is the two-dimensional fractal dimension [20,21]. Densely packed aggregates have a high fractal dimension $\left(D_{2} \approx 2\right)$, while lower fractal dimension results from large, highly branched and loosely bound structures.

There is no established method for predicting the values of fractal parameters for aggregates formed by suspended sediment particles in the shallow lake. In order to investigate the morphological characteristics of suspended particles and to understand the relation between adsorption behaviors of phosphorus and fractal dimensions of particles, the resuspension processes of sediment particles and phosphate adsorption were studied under different disturbing intensity by utilizing simulative conditions. Processes of resuspension, flocculation and precipitation of particles were observed on-line, and the image analysis of particle morphology was applied.

\section{Material and methods}

\subsection{Sediment sample}

The surface sediments were collected from the Meiliang Bay of Taihu Lake and the sampling site was called T6 $\left(31^{\circ} 30^{\prime} 19^{\prime \prime} \mathrm{N}\right.$, $120^{\circ} 7^{\prime} 52^{\prime \prime} \mathrm{E}$ ) and showed in Fig. 1.

Taihu Lake is a large typical shallow lake with an area of $2338 \mathrm{~km}^{2}$, the annual average water depth of $2 \mathrm{~m}$. The resuspension of sediments in Taihu Lake plays a pivotal role on ecological system, while the hydrodynamic disturbance influences on the sediments suspension, nutrient release and adsorption significantly [22]. Meiliang Bay (at the northern tip of the lake) receives large amounts of untreated effluents from the township industries in Changzhou and Wujin mainly through the Zhihugang River.

The top $5 \mathrm{~cm}$ of sediment was extruded into plastic bags. The sediment was homogenized and immediately brought to the laboratory and stored in the dark at $4{ }^{\circ} \mathrm{C}$ for preliminary laboratory handling.

\subsection{Apparatus}

A jar stirrer was designed as the disturbing equipment (Fig. 2). The experimental equipment contained stirrer (the length and

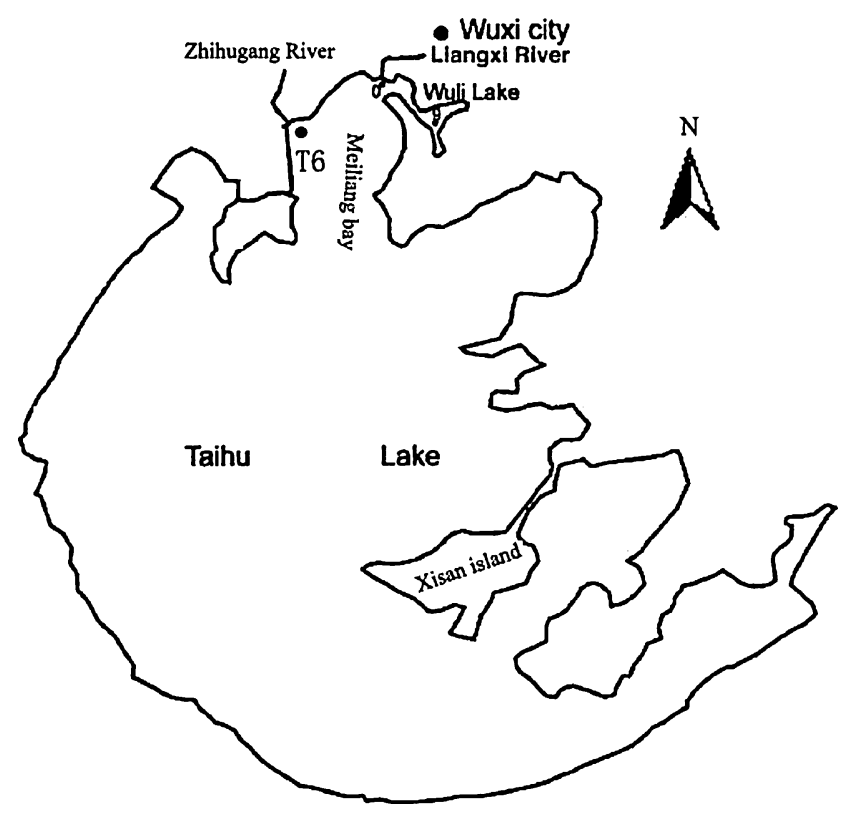

Fig. 1. The schematic of sampling location T6. 

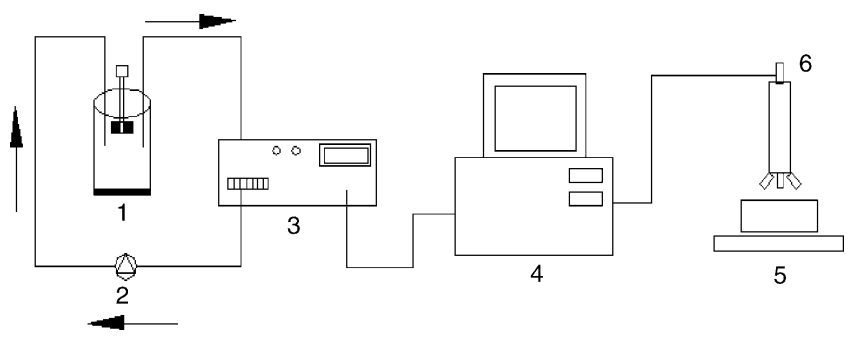

Fig. 2. The diagram of the simulative disturbing equipment. 1, Stirrer and beaker; 2, peristaltic pump; 3, PDA2000; 4, computer; 5, microscope; 6, CCD camera.

height of blade is 50 and $10 \mathrm{~mm}$, the diameter and height of beaker is 100 and $180 \mathrm{~mm}$ ), flocculation monitor (PDA2000, Rank Brothers Ltd., Cambridge, UK), and microscope with high solution CCD camera (B2 series system microscopes, Motic Incorporation, USA).

\subsection{Dynamic monitoring}

For dynamic monitoring, a sample from beaker was circulated through transparent plastic tubing of $3 \mathrm{~mm}$ inner diameter by a peristaltic pump. The peristaltic pump was located after the PDA to avoid the effects of possible aggregate breakage. The sample passed through the PDA detector where the light transmitted through the flowing suspension was directly monitored and then flowed back to the beaker. A sensitive indication of the degree of aggregation of a suspension could be shown by the ratio of the root mean square (rms) value to the average transmitted light intensity (dc) value [23]. The ratio value was called the Flocculation Index (FI) in this paper. The FI value was strongly correlated with suspended particles size and always increased with particles growing larger [24]. Although it was not possible to derive quantitative information on suspended particles size, the FI value provided a very useful relative indication of aggregates growth, breakage and re-growth, and allowed comparisons to be made between different disturbing conditions.

\subsection{Preparation of simulative water}

One hundred grams homogeneous wet sediments were put into the bottom of the cylindrical beaker and the overlying water was $1000 \mathrm{ml}$ deionized water, which was carefully introduced into the beaker by peristaltic pump. Considering the average concentration of phosphate was between 0.001 and $0.146 \mathrm{mg} / \mathrm{l}$ and the maximum concentration was $0.29 \mathrm{mg} / \mathrm{l}$ in Taihu Lake [25], the phosphate concentration of simulative water was $0.20 \mathrm{mg} / 1$ by adding $50 \mathrm{mg} / \mathrm{l} \mathrm{NaH} \mathrm{PO}_{4}$ (analytical grade) to $1000 \mathrm{ml} \mathrm{sim-}$ ulative water. Therefore, the phosphate concentration of simulative water was close to the practical water of Taihu Lake. When all the steps were finished, the simulative water settled for $12 \mathrm{~h}$ before used.

\subsection{Procedures}

In order to simulate the disturbing condition formed by wave and current, the rotary speed of blade was set at 60,100 and
Table 1

The list and symbols of simulative conditions

\begin{tabular}{llll}
\hline Symbols & Step 1 & Step 2 & Step 3 \\
\hline T6-60 & $\begin{array}{l}\text { 60 rpm 30 min weak } \\
\text { disturbance }\end{array}$ & $\mathrm{N}$ & $\mathrm{N}$ \\
T6-100 & $\begin{array}{l}\text { 100 rpm 30 min } \\
\text { medium disturbance } \\
\text { 120 rpm 30 min heavy } \\
\text { Tisturbance }\end{array}$ & $\mathrm{N}$ & $\mathrm{N}$ \\
T6-120-S & $\begin{array}{l}\text { 120 rpm 30 min heavy } \\
\text { disturbance }\end{array}$ & $\begin{array}{l}\text { 60 rpm 30 min weak } \\
\text { disturbance }\end{array}$ & $\begin{array}{l}\text { No min } \\
\text { settling }\end{array}$ \\
\hline
\end{tabular}

$\mathrm{N}$ denotes that the phase is not in presence.

$120 \mathrm{rpm}$ individually and these three rotary speeds were represented as low, medium and high disturbing intensities. For continuous dynamic tests, the sample was pumped from the beaker at a flow rate of $20 \mathrm{ml} / \mathrm{min}$ and the PDA instrument monitored average and fluctuating components of the transmitted light intensity. On-line data were acquired by a PC at an interval of $5 \mathrm{~s}$. The concentration of $\mathrm{P}$, turbidity and morphological parameters of suspended particles were measured under different disturbing time, and the sampling site of overlying water was $20 \mathrm{~mm}$ under water surface. The sampling water was filtrated by $0.45 \mu \mathrm{m}$ membrane, and the soluble $\mathrm{P}$ concentration was determined by the molybdenum blue complex method according to Murphy and Riley [26]. Moreover, the turbidity of overlying water was measured by turbidimeter $(2100 \mathrm{~N}$, Hach, USA) and temperature was kept at $20 \pm 3{ }^{\circ} \mathrm{C}$ on all of the experiments.

At given time intervals, about $2 \mathrm{ml}$ suspension was gently collected from the beaker by using a glass tube with $5 \mathrm{~mm}$ inner diameter, and then moved to a cell mounted on the microscopic camera for image analysis of the particles in the suspension. Because the sampling tube was sufficiently large and the cell was previously filled with an amount of deionized water, no breakage or further growth would happen under careful operation.

Different disturbing conditions and their representative symbols were listed in Table 1. Two typical disturbing conditions, following heavy disturbing intensity by high wind velocity were simulated. One was static condition without wind and was represented as T6-120-S, the other was weak disturbing intensity with slow wind velocity and was represented as T6-120-60-S. In T6-120-S, there was non-disturbance in the whole $60 \mathrm{~min}$ after $30 \mathrm{~min} 120 \mathrm{rpm}$ heavy disturbing intensity. In comparison, for the T6-120-60-S, there were two parts after $30 \mathrm{~min} 120 \mathrm{rpm}$ heavy disturbing intensity, 30 min weak disturbing intensity with $60 \mathrm{rpm}$ was first, and then the other $30 \mathrm{~min}$ with non-disturbance was next.

\subsection{Image analysis}

With the picture of particles captured by the microscopic digital camera connected to the PC, the projected area, characteristic length and shape factors were calculated by image analysis software (Mivnt, Daheng, Beijing, China). In this work, the long axis of the fitted ellipse, which was fitted to the particles image such that the moment of inertia of the ellipse and the image are equal, was taken as the characteristic length. The 


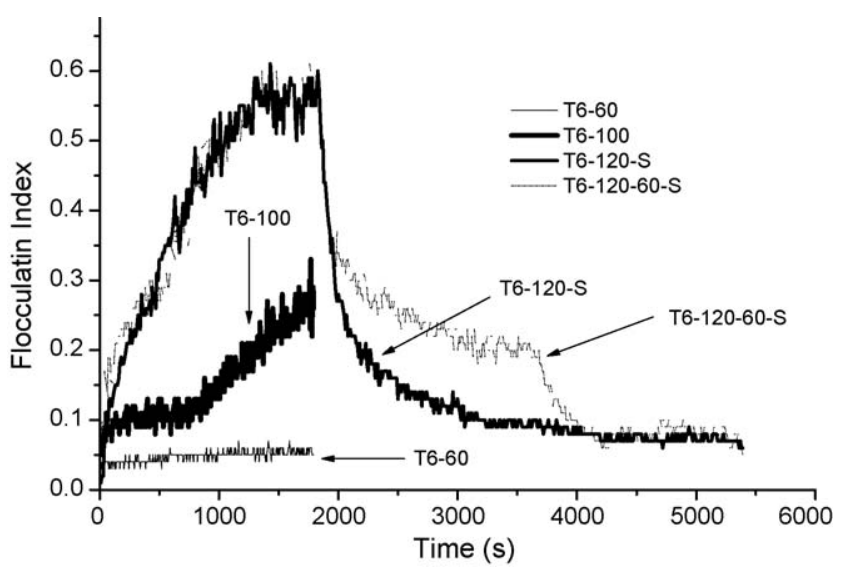

Fig. 3. The variation of FI value under different disturbing conditions.

two-dimensional fractal dimension was calculated by regression analysis of the logarithm of the projected area versus the logarithm of the long axis of the fitted ellipse as suggested by Eq. (1).

\section{Results and discussion}

\subsection{FI and turbidity}

Under different disturbing intensities, sediment particles suspended, accompanied by variation of FI value and turbidity fluctuating (as shown in Figs. 3 and 4).

When the rotary speed was at $60 \mathrm{rpm}$, FI value remained approximately constant and was independent of the disturbance. It turned out that the surface sediments do not suspended under the weak disturbing intensity with $60 \mathrm{rpm}$. As distinguished from $60 \mathrm{rpm}$, FI value increased rapidly to 0.1 at the beginning of disturbance at medium disturbing intensity with $100 \mathrm{rpm}$. After the increasing at the beginning, FI value fluctuated at 0.1 and remained almost constant. The results showed that the surface sediments were sheared and suspended to the overlying water, thus, the disturbing intensity with $100 \mathrm{rpm}$ was supposed as the critical intensity. More specifically, when the disturbing inten-

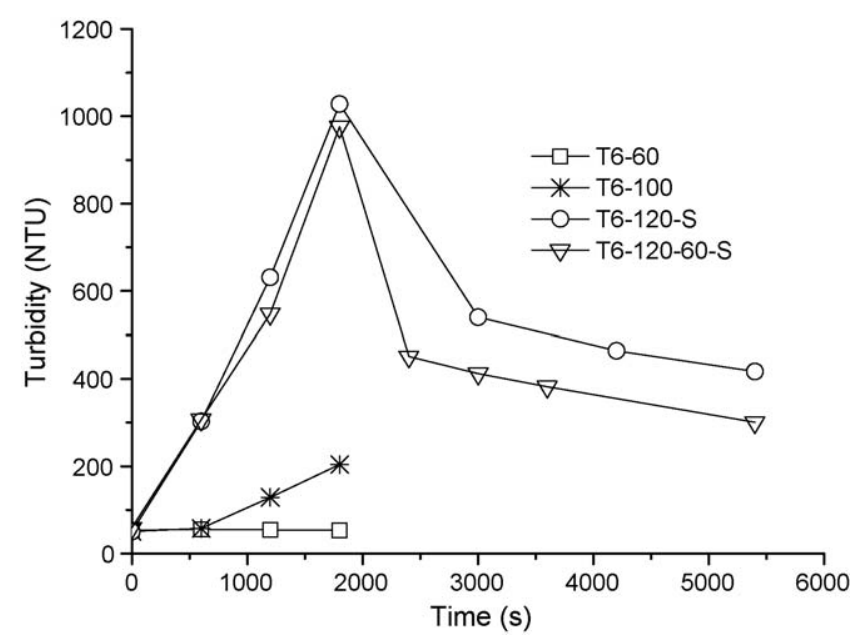

Fig. 4. The turbidity curve under different disturbing conditions. sity above $100 \mathrm{rpm}$, sediment particles could suspend. On the contrary, sediment could not suspend to the overlying water when the disturbing intensity below $100 \mathrm{rpm}$. However, FI value increased rapidly after $12 \mathrm{~min}$ and reached 0.25 at the end of disturbance with $100 \mathrm{rpm}$. This phenomenon was attributed to the aggregates growth by the flocculation of relative small particles. Particles in the suspension had the probability of colliding and forming relative larger aggregates under moderate disturbance; thus, it could be predicted that a higher FI value would be achieved if the disturbing time were longer.

As rotary speed was at $120 \mathrm{rpm}$, the sediments suspended swiftly, at the same time, the turbidity of suspension crept steeply. The result showed that the FI value exhibited obvious growth to 0.6 after $30 \mathrm{~min}$ disturbance; we concluded that the sediments were disturbed sufficiently and great deals of particles suspended to the overlying water. At the heavy disturbing intensity at $120 \mathrm{rpm}$, not only the surface sediment particles suspended, but also the deeper sediment particles were disturbed.

At $120 \mathrm{rpm}$, two different processes were compared. These two processes had been introduced in detail in Section 2. FI value obtained on the process that existing $30 \mathrm{~min}$ weak disturbing intensity with $60 \mathrm{rpm}$ was higher than which in non-disturbance. When the weak disturbance after the heavy disturbing intensity with $120 \mathrm{rpm}$ presented, FI value decreased slightly. On the contrary, FI value decreased sharply when there was nondisturbance following the heavy disturbing intensity. The difference between the two processes showed that the smaller particles suspended by heavy disturbing intensity can be flocculated to larger aggregates in weak disturbance, however, these smaller particles cannot form larger in a relative higher disturbing intensity, even there were some larger particles and which would be broken since the heavy shear-force introduced. Nevertheless, in the non-disturbance condition, the further growth of smaller particles was not occurred because there was not enough probability of collision for smaller particles flocculating to larger aggregates.

From the results of turbidity, there was no obvious variation when the disturbing intensity was at $60 \mathrm{rpm}$. It was demonstrated that the surface sediments had not been sheared enough. As the rotary speed increased to $100 \mathrm{rpm}$, there was no variation of turbidity in the first $10 \mathrm{~min}$ also, but turbidity increased to $200 \mathrm{NTU}$ after the beginning $10 \mathrm{~min}$, this result showed that the surface sediments were under the critical disturbing condition. Finally, when the rotary speed was changed to $120 \mathrm{rpm}$, the turbidity increased sharply greater than 1000 NTU, the sediments were sheared sufficiently and suspended on a large scale. All of the conclusions from turbidity variation were consistent with which draw from FI value.

Although, the FI value, of the weak disturbance after $120 \mathrm{rpm}$, was higher than which of non-disturbance, turbidity of the former was lower than which of the latter. By contrasting, it should be pointed that the smaller particles, which precipitated noneasily, flocculated to larger aggregates and it was due to the existence of weak disturbance, and then these aggregates precipitated easily compared to the small particles, and thus, turbidity of suspension would be lower. This result was in agreement with the fact that, the transparency of suspension in shallow 


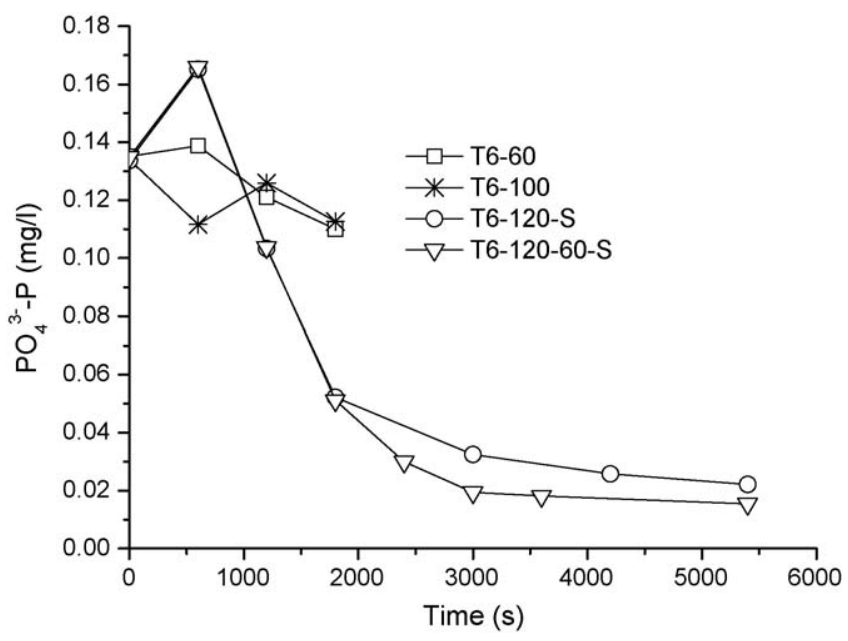

Fig. 5. The soluble $\mathrm{P}$ concentration of overlying water under different disturbing conditions.

lakes would be higher in the occurrence of slow wind velocity after high wind intensity disturbance than which in the non-wind disturbance after high wind intensity disturbance.

\subsection{Phosphate adsorption}

After settling at room temperature for $12 \mathrm{~h}$, the $\mathrm{P}$ concentration decreased to $0.13 \mathrm{mg} / \mathrm{l}$, and it could be explained as the adsorption of sediments. Therefore, the original $\mathrm{P}$ concentration in the adsorption experiments was close to $0.13 \mathrm{mg} / 1$ and less than $0.20 \mathrm{mg} / \mathrm{l}$.

The variation of $\mathrm{P}$ concentration of overlying water was shown schematically in Fig. 5. There was no remarkable change at $60 \mathrm{rpm}$, on account of the surface sediments were not sheared sufficiently, but the $\mathrm{P}$ concentration increased slightly in $10 \mathrm{~min}$ and the reason might be the desorption from sediments, which adsorbed the phosphate during $12 \mathrm{~h}$ deposition, as a result, the sediments became a "source"; As the disturbing intensity changed to $100 \mathrm{rpm}$, the $\mathrm{P}$ concentration decreased at $10 \mathrm{~min}$, as a consequence of the surface sediments suspended observably and the phosphate adsorbed by the suspended aggregates. After that, the $\mathrm{P}$ concentration fluctuated because of the variation of desorption and adsorption.

When the disturbing intensity increased to $120 \mathrm{rpm}$, a great number of particles suspended to the overlying water, which indicated that the sediments were sufficiently disturbed. Two different variations of $\mathrm{P}$ concentration were observed, the $\mathrm{P}$ concentration enhanced to $0.165 \mathrm{mg} / \mathrm{l}$ at the end of first $10 \mathrm{~min}$, but, after that, the $\mathrm{P}$ concentration decreased and stabilized at $0.02 \mathrm{mg} / \mathrm{l}$ after settling. The reason of increasing $\mathrm{P}$ concentration in the first 10 min was desorption from the sediments; however, the reason of $\mathrm{P}$ concentration reduction afterwards was adsorption by the suspended particles. Comparing the behavior of phosphorus adsorption by suspended aggregates formed by two different processes: T6-120-S and T6-120-60-S, after $30 \mathrm{~min}$ heavy disturbance with $120 \mathrm{rpm}$, we observed that the $\mathrm{P}$ concentration was lower in T6-120-60-S than which in T6-120$\mathrm{S}$, thus, the diversity of $\mathrm{P}$ concentration between the two different

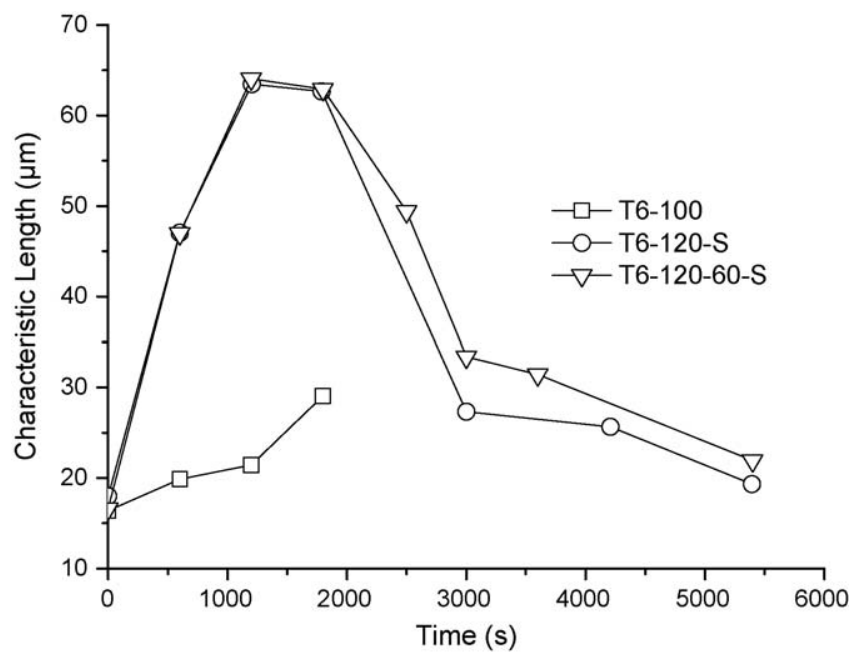

Fig. 6. The characteristic length of suspended particles under different disturbing conditions.

disturbing conditions was necessary to be discussed further. As mentioned above, the fractal characteristics of suspended particles and their influence on the behavior of phosphorus adsorption needed to be investigated.

\subsection{Morphological analysis of suspended particles}

As shown in Fig. 6, the original characteristic length of suspended particles was about $16.5 \mu \mathrm{m}$ before the disturbance occurred. When the rotary speed was $100 \mathrm{rpm}$, the particles of surface sediments suspended slightly and the characteristic length increased simultaneously. It was in accordance with what shown in the FI curves. After 30 min disturbance, the characteristic length grew up to $30 \mu \mathrm{m}$, it was nearly double size of original particles. As the rotary speed was $120 \mathrm{rpm}$, the characteristic length of formed aggregates increased sharply and attained to $60 \mu \mathrm{m}$ after $30 \mathrm{~min}$ disturbance. The distinction of characteristic length between T6-120-S and T6-120-60-S was in approximate agreement with FI curves, and, T6-120-60-S had larger characteristic length than T6-120-S after 30 min high disturbance. The result showed that the smaller particles could be flocculated to larger aggregates in T6-120-60-S.

Fig. 7 was the representative images of suspended particles in T6-120-S under different time. It could be seen from Fig. 7, particles of various size and shape were formed under different disturbing phases. It could also be clear seen that the shape of suspended particles was not spherical. The ratio of long axis to short axis of fitted ellipse, $l / w$, was between 1.43 and 1.64. The morphological parameters of suspended particles were listed in Table 2. As summarized in Table 2, the two-dimensional fractal dimensions were between 1.65 and 1.92. Generally speaking, highly branched and loosely bound structures have lower fractal dimension, on the contrary, packed and regular structures have higher fractal dimension. The fractal dimension of original particles without disturbance was 1.65 , but fractal dimension grew up and was larger than 1.65 at all of three disturbing conditions. It turned out that the relatively loose structures were evolved into more packed aggregates under the disturbing force. 


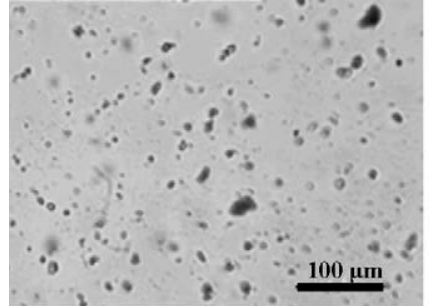

(a)

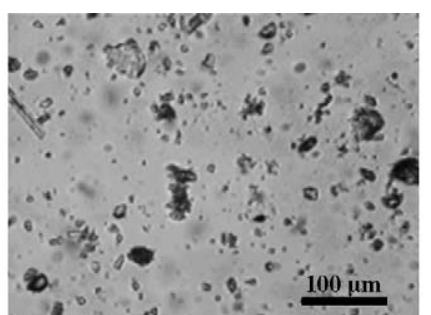

(b)

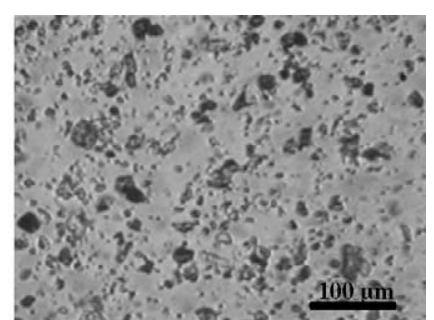

(c)

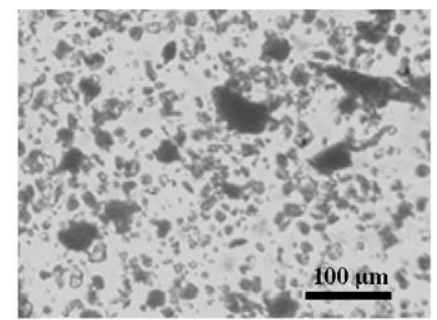

(d)

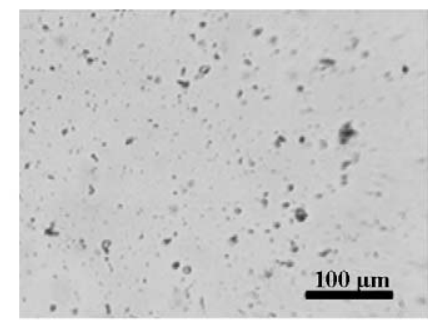

(e)

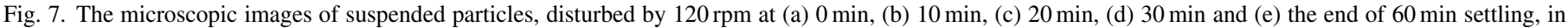
T6-120-S

Table 2

The morphological characteristics of suspended particles

\begin{tabular}{lrlll}
\hline Symbol & Time $(\min )$ & $l / w$ & $D_{2}$ & $R^{2}$ \\
\hline T6-100 & 0 & 1.50 & 1.65 & 0.97 \\
T6-120-S & 30 & 1.43 & 1.86 & 0.98 \\
& 0 & 1.61 & 1.65 & 0.96 \\
& 30 & 1.47 & 1.91 & 0.91 \\
T6-120-60-S & 60 & 1.50 & 1.81 & 0.80 \\
& 90 & 1.47 & 1.87 & 0.98 \\
& 0 & 1.49 & 1.65 & 0.89 \\
& 30 & 1.57 & 1.92 & 0.91 \\
& 60 & 1.64 & 1.65 & 0.91 \\
& 90 & 1.50 & 1.67 & 0.81 \\
\hline
\end{tabular}

$l / w$ : the ratio of long axis to short axis of fitted ellipse; $D_{2}$ : the two-dimensional fractal dimension; $R^{2}$ : relative coefficient.

It was interesting to point out the distinction of fractal dimensions between T6-120-S and T6-120-60-S on $60 \mathrm{~min}$, the fractal dimension of T6-120-S was 1.81 which was larger than 1.65 of T6-120-60-S. Thus, the result showed that the suspended particles could flocculate to larger aggregates when there was weak disturbance occurring after heavy disturbance, while, these new aggregates had highly branched and loosely bound structures with larger size. Therefore, not only the precipitated performance was enhanced, but also the capability of adsorption for phosphate was promoted because there were more adsorption locations in the new aggregates with more opened structure. As mentioned above, the distinction of turbidity of suspension and the behavior of phosphate adsorption between two different disturbing conditions could be explained from particle morphology.

\section{Conclusions}

The resuspension, flocculation and precipitation of sediment particles in shallow lakes were influenced by hydrodynamic dis- turbance significantly, while, these processes played an important role in the variation of nutrients concentration in water system. When there were heavy disturbance, which usually was introduced by wind-induced waves, the sediment particles suspended obviously and the particles number in overlying water increased directly. As a result of particles suspension, the phosphate was adsorbed rapidly by the suspended particles and the concentration of phosphate in the overlying water decreases sharply. In most cases, the processes of resuspension, flocculation and precipitation were accompanied by particles morphological alteration; however, the morphological change of particles affected the precipitated performance and the behaviors of nutrient adsorption. Therefore, the particle morphology provided a new method in studying the sediment particles and the behaviors of nutrient adsorption and release, especially, in shallow lakes.

\section{Acknowledgements}

The study was funded by the important project of knowledge innovation program of Chinese Academy of Sciences (KZCX1SW-12) and NSF of China under 50578155.

\section{References}

[1] D.W. Schindler, Evolution of phosphorus limitation in lakes, Science 195 (1977) 260-262

[2] K.E. Havens, C.L. Schelske, The importance of considering biological processes when setting total maximum daily loads (TMDL) for phosphorus in shallow lakes and reservoirs, Environ. Pollut. 113 (2001) $1-9$.

[3] K.R. Reddy, M.M. Fisher, D. Ivanoff, Resuspension and diffusion flux of nitrogen and phosphorus in a hypereutrophic lake, J. Envion. Qual. 25 (1996) 363-371

[4] P. Kristensen, M. Søndergaard, E. Jeppesen, Resuspension in a shallow eutrophic lake, Hydrobiologia 228 (1992) 101-109. 
[5] L. Håkanson, M. Jansson, Principles of Lake Sedimentology, SpringerVerlag, Berlin, 1983.

[6] G. Blom, H.S. Elisabeth, R.H. Van Duin, Aalderink, L. Lijklema, C. Toet, Modelling sediment transport in shallow lakes-interactions between sediment transport and sediment composition, Hydrobiologia 235/236 (1992) $153-166$.

[7] N. Hawley, B.M. Lesht, Sediment resuspension in Lake St. Clair, Limnol. Oceanogr. 37 (1992) 1720-1737.

[8] M. Søndergaard, P. Kristensen, E. Jeppesen, Phosphorus release from resuspended sediment in the shallow and wind-exposed Lake Arreso, Denmark, Hydrobiologia 228 (1992) 91-99.

[9] M. Pejrup, J. Valeur, A. Jensen, Vertical flux of particulate matter in Aarhus Bight, Denmark, Cont. Shelf Res. 16 (1996) 1047-1064.

[10] M. Van Der Loeff, M. Rutgers, B.P. Boudreau, The effect of resuspension on chemical exchanges at the sediment-water interface in the deep sea-A modeling and natural radiotracer approach, J. Mar. Syst. 11 (1997) 305-342.

[11] G. Michelcic, B. Surijia, M. Juracic, et al., History of the accumulation of trace metals in sediments of the saline Rogoznica Lake, Sci. Total Environ. 182 (1996) 105-115.

[12] G.L. Carper, R.W. Bachmann, Wind resuspension of sediments in a prairie lake, Can. J. Fish. Aquat. Sci. 41 (1984) 1763-1767.

[13] L. Bengtsson, T. Hellstrom, Wind induced resuspension in a small shallow lake, Hydrobiologia 24 (1992) 163-172.

[14] B.G. Ogilvie, S.F. Mitchell, Does sediment resuspension have persistent effects on phytoplankton? Experimental studies in three shallow lakes, Fresh Biol. 40 (1998) 51-63.
[15] B.Q. Qin, W.P. Hu, J.S. Zhang, Dynamic mechanism of sediments suspension and conceptual model for internal pollution source in Taihu Lake, Chin. Sci. Bull. 48 (1998) 1822-1831 (in Chinese).

[16] C.X. Fan, L. Zhang, B.Q. Qin, Calculation for dynamic phosphorus release from wind-induced suspended particles in Taihu Lake, Sci. China Ser. DEarth Sci. 33 (2003) 760-768 (in Chinese).

[17] G.W. Zhu, B.Q. Qin, L. Zhang, et al., Wave effects on nutrient release of sediments from Lake Taihu by flume experiments, J. Lake Sci. 17 (2005) 61-68 (in Chinese).

[18] Q. Jiang, B.E. Logan, Fractal dimensions of aggregates determined from steady-state size distributions, Environ. Sci. Technol. 25 (1991) 2031-2038.

[19] C.P. Johnson, X.Y. Li, B.E. Logan, Settling velocities of fractal aggregates, Environ. Sci. Technol. 30 (1996) 1911-1918.

[20] R.K. Chakraborti, J.F. Atkinson, J.E. Van Benschoten, Characterization of alum floc by image analysis, Environ. Sci. Technol. 34 (2000) 3969-3976.

[21] J.R. Kilps, B.E. Logan, A.L. Alldredge, Fractal dimensions of marine snow determined from image analysis of in situ photographs, Deep-Sea Res. 41 (1994) 1159-1169.

[22] S.P. Sun, Y.P. Huang, Taihu Lake, Ocean Press, Beijing, 1993 (in Chinese).

[23] J. Gregory, D.W. Nelson, Monitoring of aggregates in flowing suspensions, Colloid Surf. 18 (1986) 175-188

[24] J. Gregory, H.J. Chung, Continuous monitoring of floc properties in stirred suspensions, J. Water Supply: Res. Technol., AQUA 44 (1995) 125-131.

[25] B.Q. Qin, W.P. Hu, et al., The evolvement and mechanism of water environment in Taihu Lake, Science Press, Beijing, 2004 (in Chinese).

[26] J. Murphy, J.P. Riley, A modified single solution method for the determination of phosphate in natural water, Anal. Chim. Acta 27 (1962) 31-36. 